\title{
Cognition-tracking-based strategies for diagnosis and treatment of minimal hepatic encephalopathy
}

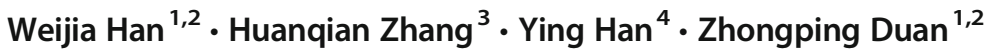 \\ Received: 4 September 2019 / Accepted: 23 January 2020 / Published online: 3 June 2020 \\ (C) The Author(s) 2020
}

\begin{abstract}
Minimal hepatic encephalopathy (MHE), which shows mild cognitive impairment, is a subtle complication of cirrhosis that has been shown to affect daily functioning and quality of life. However, until 2014, relevant guidelines do not give much attention to the diagnosis and treatment of MHE, resulting in patients being ignored and denied the benefits of treatment. In this review, we summarize recent cognition-based research about (1) alteration of nerve cells, including astrocytes, microglial cells and neurons, in mild cognitive impairment in MHE; (2) comparison of methods in detecting cognitive impairment in MHE; and (3) comparison of methods for therapy of cognitive impairment in MHE. We hope to provide information about diagnosis and treatment of cognitive impairment in patients with MHE.
\end{abstract}

Keywords Cognitive impairment $\cdot$ Diagnosis and treatment $\cdot$ Minimal hepatic encephalopathy $\cdot$ Nerve cells

$\begin{array}{ll}\text { Abbreviations } \\ \text { ALFF } & \text { amplitude of low frequency fluctuation } \\ \text { ANT } & \text { animal naming test } \\ \text { CFF } & \text { critical flicker frequency } \\ \text { CHO } & \text { cholinesterase } \\ \text { DA } & \text { dopamine } \\ \text { EEG } & \text { electroencephalogram } \\ \text { eNCT } & \text { electronic number connection test } \\ \text { GABA } & \text { gama-aminobutyric acid } \\ \text { GLU } & \text { glutamine } \\ \text { HE } & \text { hepatic encephalopathy } \\ \text { ICT } & \text { inhibitory control test } \\ \text { IL } & \text { interleukin } \\ \text { LOLA } & \text { L-Ornithine L-aspartate }\end{array}$

Zhongping Duan duan2517@163.com

1 Difficult \& Complicated Liver Diseases and Artificial Liver Center, Beijing Youan Hospital, Capital Medical University, Beijing 100069, China

2 Beijing Municipal Key Laboratory of Liver Failure and Artificial Liver Treatment Research, Beijing, China

3 Yidu Central Hospital of Weifang Medical College, Shandong, China

4 Department of Immunologic Liver Disease, Beijing YouAn Hospital, Capital Medical University, Beijing, China

$\begin{array}{ll}\text { IR } & \text { insulin resistance } \\ \text { MD } & \text { mean diffusivity; } \\ \text { MHE } & \text { minimal hepatic encephalopathy } \\ \text { NCT } & \text { number connect test } \\ \text { MRI } & \text { magnetic resonance imaging } \\ \text { PG } & \text { prostaglandin } \\ \text { PHES } & \text { psychometric hepatic encephalopathy score } \\ \text { RCT } & \text { randomized controlled trial } \\ \text { TNF } & \text { tumor necrosis factor }\end{array}$

\section{Introduction}

Minimal hepatic encephalopathy (MHE), which affects 30$55 \%$ of cirrhosis patients, is a subtle complication of cirrhosis that may have a detrimental effect on daily functioning. In the MHE phase, patients show mild cognitive impairment, which lead to deficits of attention, and psychomotor slowing (Arias et al. 2015; Metwally et al. 2019).

However, only half of clinicians had studied their cirrhosis patients for MHE, and 38\% had never screened patients for MHE (Ridola et al. 2018). Until 2014, relevant guidelines did not recommend routine screening for MHE nor were the patients treated except on a case-by-case basis. Patients with MHE might be ignored and denied the benefits of treatment. However, researchers have shown the need to screen and treat 
patients with neurocognitive impairment associated with MHE (Vilstrup et al. 2014).

MHE is often undiagnosed for the following reasons: (1) diagnostic criteria have not been standardized; (2) there is no overt clinical manifestation in patients with MHE; and (3) hyperammonemia is present with inflammation and certain levels of ammonemia (Felipo et al. 2012; Jiao et al. 2017; Stinton and Jayakumar 2013). In terms of treatment, not all clinicians have already applied the treatment of MHE patients, because the treatment of MHE has not been included in the guidelines (Vilstrup et al. 2014).

Depending on technological progress, researchers have introduced cognition-based methods to detect and treat MHE. In this review, we summarize: (1) the relationship between cognitive impairment and nerve cell injury; (2) comparison of diagnostic methods for MHE; and (3) comparison of therapeutic methods for MHE.

\section{Nerve cell injury in MHE: cognition impairment}

During MHE, the main contributor to cognitive impairment is hyperammonemia. In patients with liver disease, ammonia accumulates in blood due to deficient activity of hepatic urea cycle enzymes. In the brain, nerve cells take up ammonia and cause cognitive impairment. For example, astrocytes take up ammonia and glutamine synthetase detoxifies ammonia into glutamine. The rapid accumulation of glutamine creates an osmotic gradient that results in astrocyte swelling (Stravitz et al. 2018).

Hyperammonemia and the changes caused by its downstream damage, such as changes in dopamine (DA) secretion, play important roles in nerve cell impairment. For example, hyperammonemia significantly reduces long-term potentiation and alters mRNA for DA receptors, which cause deficits in disturbed synaptic plasticity and novelty acquisition in hippocampal and corticostriatal pathways involved in goaldirected and learning behavior (Chepkova et al. 2017). Besides, the alteration of Gama-aminobutyric acid (GABA) also plays important roles in nerve cell impairment. GABA is the inhibitory nerve conduction in the brain. When the brain is over-excited, GABA can play the restrain role and eliminates the state of anxiety. Anxiety, insomnia, fatigue, anxiety and other symptoms can occur when GABA is lacking. Hyperammonemia is associated with increased membrane expression of the GABA transporter. Increased GABAergic tone in the cerebellum impairs motor coordination and learning ability in the Y maze. In this part, we summarize the changes in nerve cells caused by hyperammonemia (Fig. 1).

\section{Astrocytes atrophy}

Astrocytes, which actively involved in dynamic signaling in the central nervous system, are the predominant type of glial cells. Astrocytes participate in a variety of essential physiological processes, including glucose metabolism, glutamate clearance, and ionic homeostasis. Astrocytes also contribute to memory formation and information processing in the brain (Dossi et al. 2018; Jackson and Robinson 2018).

Under the influence of DA, astrocytes undergo pathological changes and affect the process of MHE. In MHE, DA stimulates production and secretion of astrocytic tumor necrosis factor (TNF)- $\alpha$. Astrocytic TNF- $\alpha$, which triggers neurodegenerative progression consequently or indirectly, resulting in cognitive impairment. Ding et al. found that low-dose DA $(10 \mu \mathrm{M})$ produced TNF- $\alpha$ in primary astrocytes, and coculture of these astrocytes and neurons exhibited neuronal apoptosis compared with control group (Ding et al. 2016). Ding et al. also demonstrated that DA induced astrocytic protein tyrosine nitration, which was attributed to NADPH oxidase subunits and induced reactive oxygen species production and $\mathrm{p} 47$ (phox) phosphorylation, but decreased neuronal-type NO synthase expression (Ding et al. 2014).

DA can cause alteration of pathways localized in astrocytes, which can lead to cognitive impairment in MHE. For example, DA activates trace amine-associated receptor 1 to down-regulate excitatory amino acid transporter- 2 in astrocytes and increase extracellular Glu levels, which interact with $\alpha$-amino-3-hydroxy-5-methyl-4-isoxazolepropionic acid receptor. DA and Glu cause memory impairment through activation of calcineurin/nuclear factor of activated $\mathrm{T}$ cells signaling in MHE (Ding et al. 2017a).

Insulin resistance (IR), which often occurs in cirrhosis patients, contributes to the MHE pathogenesis. Ding et al. found that the final production of neurotrophic factors, including PI3K/AKT signaling pathway to the phosphorylation of NMethyl-d-Aspartate receptors and downstream activation of the CaMKIV/CREB pathway, was impaired in MHE rats (Ding et al. 2018).

\section{Microglial alteration}

Microglia are critical for developmental processes and maintenance of neural homeostasis. In response to injury or insult, microglia acquires complex and diverse phenotypes, allowing them to participate in cytotoxic responses as well as in immunoregulation or injury resolution. Detrimental microglial phenotypes are produced by pro-inflammatory cytokines interleukin (IL)-1 $\beta$, Toll-like-receptor (TLR)-4 agonist lipopolysaccharide, and TNF- $\alpha$. These pro-inflammatory microglia are characterized by immune-potentiating abilities, antigenpresenting and microbicidal (Fumagalli et al. 2018). 


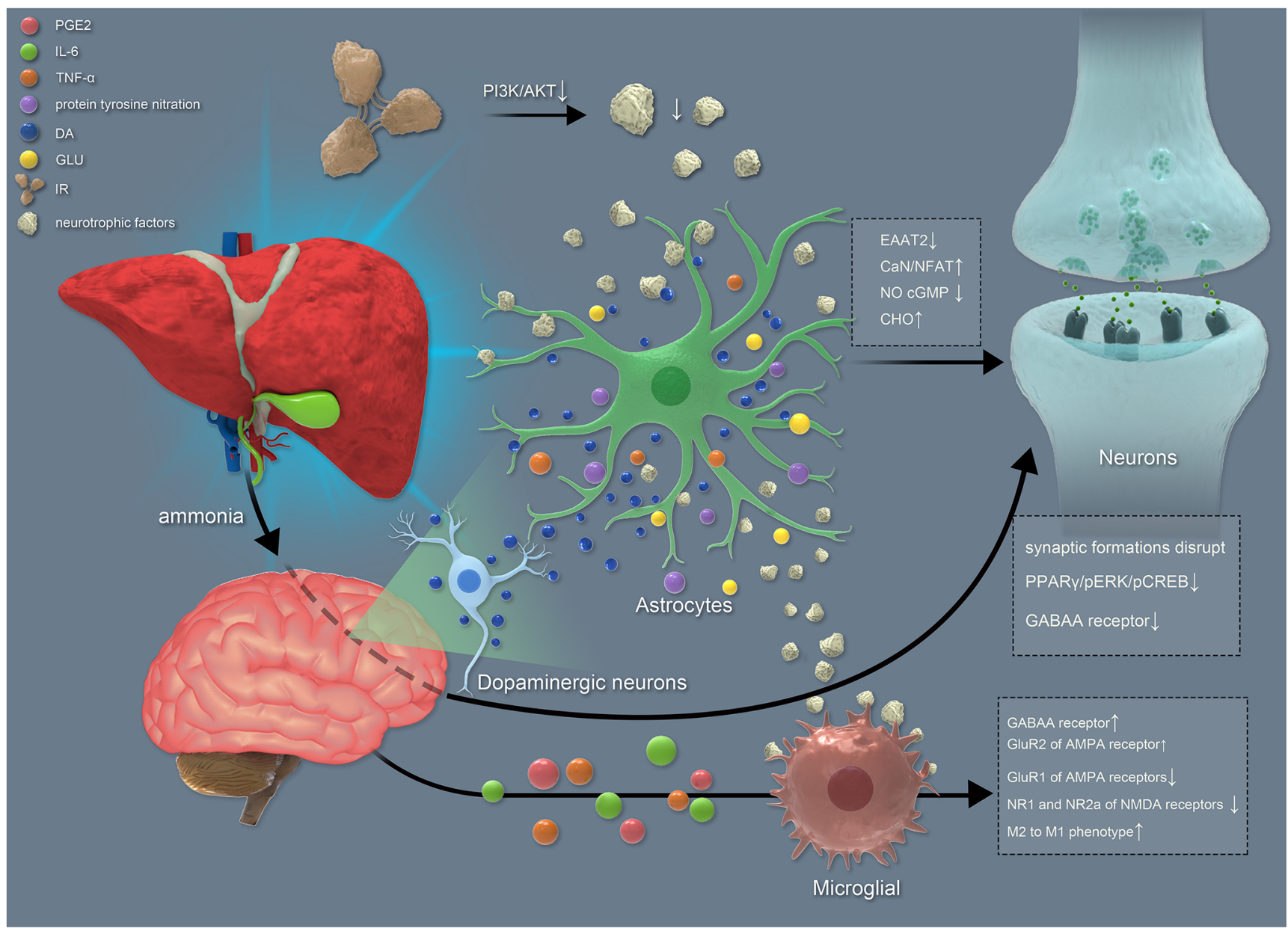

Fig. 1 MHE caused by hyperammonemia. Ammonia through the blood brain barrier into the brain, promote DA release. Then, DA promotes increased extracellular GLU and astrocytes change, such as EAAT $\uparrow$. Furthermore, it can lead to neural apoptosis. DA can also lead to increased release of inflammatory mediators, such as IL6, which can

Hyperammonemia caused reversible and rapid induction of peripheral inflammation, with increased TNF- $\alpha$, proinflammatory prostaglandin (PG)-E2 and IL-6. And hyperammonemia also caused reduced Anti-inflammatory IL-10 and microglia activation in hippocampus. Increased TNF- $\alpha$ and IL- $1 \beta$ levels and phosphorylation (activity) of p38 cause GABAergic and glutamatergic neurotransmission. For example, membrane expression of GluR2 of AMPA receptor and subunits $\alpha 1$ of etc. GABAA receptor is increased, while expression of subunits GluR1 of AMPA receptors and NR1 and NR2a of NMDA receptors is reduced. These altered membrane expression receptors are associated with hyperammonemia-induced microglial activation. And are responsible for impairment of spatial learning and altered neurotransmission in the radial maze. In turn, these inflammatory injuries contribute to microglial differentiation from antiinflammatory M2 to pro-inflammatory M1 phenotype (Agusti et al. 2011; Balzano et al. 2019; Hernandez-Rabaza et al. 2015; Hernandez-Rabaza et al. 2016). lead to signal transduction alteration, such as GABBA receptor $\uparrow$. These alterations can lead to neuron damage. Ammonia can also directly cause signal transduction changes and neuron damage.IR also can lead to neurotrophic factors production $\downarrow$, which impaired astrocytes. DA: dopamine; GLU: glutamine; IL: interleukin

\section{Neurons injury}

In the brain, most neurons are generated during embryogenesis and are not replaced frequently. These neurons need to live for the lifetime of the individual, because they were unable to remove dysfunctional proteins and organelles. So, it is exceptionally vulnerable for neuronal proteins and organelles to overuse and damage (Kulkarni and Maday 2018).

Cholinesterase $(\mathrm{CHO})$ is involved in the perturbation of neural synaptogenesis. Cholinesterase $(\mathrm{CHO})$ overload in combination with DA burden elicits memory loss and cognitive decline via the peroxisome proliferatoractivated receptor (PPAR) $\gamma /$ extracellular signalregulated kinase (ERK)/CREB pathway in MHE. In turn, DA triggers $\mathrm{CHO}$ biosynthesis via activation of the C-Jun $\mathrm{N}$-terminal kinase $3 /$ sterol regulatory element-binding protein 2 signaling pathway in primary cultured astrocytes. Zhuge et al. found that $\mathrm{CHO}$ secreted from 
astrocytes stimulated secretion of DA from primary cultured neurons. PPAR $\gamma / \mathrm{pERK} / \mathrm{pCREB}$ expression was decreased by DA-induced synergistic leads to synergistic synaptic impairment in (Zhuge et al. 2019).

\section{Neuroinflammation}

Neuroinflammation in hippocampus impairs memory and spatial learning. Neuroinflammation in cerebellum impairs learning in a $\mathrm{Y}$ maze and motor co-ordination. Hyperaminemia triggers neuroinflammation by activating microglia and increasing markers associated with impaired cognitive function (Cabrera-Pastor et al. 2019; Malaguarnera et al. 2019). Cabrera-Pastor demonstrated that hyperammonemia induced neuroinflammation was related to impaired memory and spatial learning in hyperammonemic rats. Chronic hyperammonemia also increased the level of IL- $1 \beta$. Increased IL-1 $\beta$ level alters neurotransmission and impairs spatial learning (Cabrera-Pastor et al. 2016; Hernandez-Rabaza et al. 2015). Balzano et al. demonstrated that hyperaminemia caused the elevation of pro-inflammatory factors and IL. This alteration was associated with glutamate receptors membrane expression and impairment of spatial memory (Balzano et al. 2019).

\section{Diagnosis of MHE: cognitive evaluation}

\section{Psychometric tests}

Many new psychometric tests have emerged in recent years, such as psychometric hepatic encephalopathy score (PHES) (Ferenci et al. 2002), Stroop app (Bajaj et al. 2013), and animal naming test (ANT) (Campagna et al. 2017). Ideal screening tests for MHE should be characterized by less time-consuming, objective outcome, independent of specialists' interpretation, simple to use and free from copyright and fees (Yoon et al. 2019).

\section{PHES}

PHES comprises of five tests and has been recognized as the gold standard for diagnosis of MHE since 1998. It is widely accepted that diagnostic of MHE is PHES score $\leq$ -5 (Ferenci et al. 2002; Luo et al. 2019; Singh et al. 2016). Tsai et al. found that PHES can be a useful tool for detecting patients with MHE in around one third of outpatients with cirrhosis (Tsai et al. 2015). Badea et al. showed the prevalence of MHE in Romanian cirrhosis patients. PHES of the healthy control group was significantly higher than that in the liver cirrhosis group (Badea et al. 2016). But Coskun et al. set -4 as the cutoff in Turkish PHES nomograms. They found that the PHES score in the cirrhotic group was $-2.18 \pm 3.3$, which was significantly lower than the center of gravity (Coskun et al. 2017). To validate widely applicable norms, future multicenter studies are needed.

\section{Stroop app}

The Stroop app score, which is based on ipad or ipod, is significant for diagnosis of MHE (Bajaj et al. 2013). The method is shown in Table 1. The Stroop app has a accuracy rate of 0.74 and is suitable for MHE screening (Yoon et al. 2019). Zeng et al. demonstrated that $>97.34 \mathrm{~s}$ for "Off" state time and $>186.63 \mathrm{~s}$ for "Off" state + "On" state time had the maximum area under the curve values in all patients. Meanwhile, "Off" state + "On" state time had the highest sensitivity with a cutoff of 186.63 s. Compared with PHES, the Stroop app is time saving, accessible, convenient, and accepted by patients and clinicians (Zeng et al. 2019).

\section{ANT}

Cognitive functions related to prefrontal anterior/ cortex cortical areas are sensitive to the ANT. Patients are asked to list as many animals as they can in $1 \mathrm{~min}$. Errors and repetitions should be excluded from the calculations (Table 1). Campagna et al. found that, in order to eliminate age interference, a simplified ANT was obtained, adding 3 animals for patients with $<8$ years of education and 6 animals if they were over 80 years old in addition (Campagna et al. 2017). Labenz et al. demonstrated that the simplified ANT may become an initial screening tool for assessment of MHE. They found that ANT was Significant lower in patients with MHE. The best discrimination between patients with and without MHE is naming $<20$ animals. But when the cutoff value is $\geq 23$ animal names, $38.5 \%$ of patients could be avoided further testing for MHE, and the negative predictive value was $84 \%$ (Labenz et al. 2019).

\section{Other tests}

The inhibitory control test (ICT) represents the ability to suppress irrelevant motor or cognitive processes, and is useful for diagnosis of MHE (Di Lemma and Field 2017; Hartmann et al. 2019). The method is shown in Table 1. Gupta et al. demonstrated that ICT is correlated with disease severity, predicts the development of $\mathrm{HE}$, and has excellent test-retest reliability. ICT was considered abnormal when there were $\geq$ 14 ICT lures. Mean ICT lures were higher and target accuracy was lower in cirrhotic patients with MHE than those without MHE. ICT had a sensitivity of $92.6 \%$ and specificity of $78.5 \%$ with an area under the receiver operating characteristic curve of 0.855 for MHE (Gupta et al. 2015). 
Table 1 Comparison of different kinds of diagnostic methods

\begin{tabular}{|c|c|c|c|}
\hline & & Method & Disadvantage \\
\hline \multirow[t]{4}{*}{ Psychometric tests } & PHES & $\begin{array}{l}\text { It comprises the number connect test (NCT)-A, NCT-B, } \\
\text { serial dotting test, line tracing test, and digit symbol test, } \\
\text { which are each scored from } 1 \text { to }-3\end{array}$ & 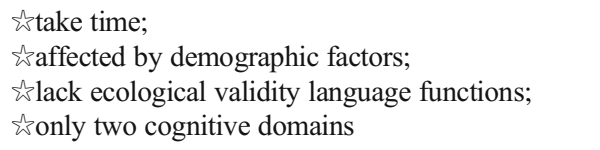 \\
\hline & Stroop app & $\begin{array}{l}\text { "Off" and "On" task are the two components depending } \\
\text { on the discordance or concordance of the stimuli. } \\
\text { Patients have } 2 \text { training runs for two components. In } \\
\text { "Off" state, pound signs (\#\#\#) presented in red, green or } \\
\text { blue, one has to respond as quickly as possible by } \\
\text { touching the matching color, which were also } \\
\text { randomized and not fixed to their respective positions. } \\
\text { This continues until a total of } 10 \text { presentations. If the } \\
\text { subject makes a mistake, the run stops and has to restart } \\
\text { again. The "Off" state continued till the subject had } \\
\text { achieved } 5 \text { correct runs. In the "On" state, the patient } \\
\text { has to touch the color of the word presented which is } \\
\text { actually the name of the color in discordant coloring. } \\
\text { The test of cognitive processing controlling for } \\
\text { psychomotor speed was subtracting the "Off" state time } \\
\text { from the "On" state time }\end{array}$ & $\begin{array}{l}\text { ¿complex } \\
\text { ţoptimal cutoff is varied }\end{array}$ \\
\hline & ANT & $\begin{array}{l}\text { In ANT test, patients were asked to list as many animals as } \\
\text { they could in } 1 \mathrm{~min} \text {. All repetitions and errors were } \\
\text { excluded from the calculations }\end{array}$ & ¿̦no significant limitatin \\
\hline & Other & $\begin{array}{l}\text { ICT: An alcohol-related or control picture was presented } \\
\text { in the centre of the screen with one of two letters } \\
\text { superimposed on one of the four corners of the picture. } \\
\text { Patients were instructed to press the space bar if the go } \\
\text { cue was present, but to withhold their response if the } \\
\text { no-go cue was present. During each trial, the picture and } \\
\text { letter remained on screen until the participant responded } \\
\text { or until a } 1500 \mathrm{~ms} \text { timeout had elapsed } \\
\text { eNCT: electronic based NCT }\end{array}$ & t ICT requires highly functional patients \\
\hline $\mathrm{CFF}$ & & $\begin{array}{l}\text { Patient is equipped with a light shade, and the red light } \\
\text { spot flashes at a ratio of } 1: 1 \text { at a frequency of } 60 \mathrm{~Hz} \text {. At } \\
\text { the beginning, the subject cannot recognize the flicker } \\
\text { because the flicker frequency is fast, and then the flicker } \\
\text { frequency gradually slows down until the subject can } \\
\text { recognize the flicker stop. }\end{array}$ & $\begin{array}{l}\text { ¿sexpensive; } \\
\text { ¿time-consuming; } \\
\text { ¿s dependent on the specialist's interpretation }\end{array}$ \\
\hline MRI & & $\begin{array}{l}\text { Marker, including mean kurtosis values, Six ROIs, ALFF } \\
\text { values and default mode network, are useful biomarkers } \\
\text { for MHE detection. }\end{array}$ & thlack of detection accuracy of the measured signal \\
\hline \multicolumn{2}{|c|}{ inflammatory cytokines } & $\mathrm{Na}$ & $\begin{array}{l}\text { tho studies on the accuracy and sensitivity } \\
\text { of its application }\end{array}$ \\
\hline
\end{tabular}

The novel electronic number connection test (eNCT) has test-retest reliability to detect cognitive function and monitor cognitive impairment in patients with cirrhosis. Wuensch et al. found that the eNCT performance was negatively correlated with PHES performance in patients with cirrhosis. Control participants showed significantly faster eNCT completion times compared with cirrhosis patients (Wuensch et al. 2017).

\section{Critical flicker frequency (CFF) and electroencephalography (EEG)}

CFF reflects dysfunction of nerve conduction in the brain. It is an objective test that avoids the deviation caused by cultural differences. The CFF method is shown in Table 1 (Wang et al. 2013). CFF is widely acknowledged as an adjunct tool for diagnosis of MHE. However, some researchers believe that CFF should be used as an adjunct to the PHES test because of its low sensitivity for detecting MHE. They found that CFF had a diagnostic accuracy of $70.6 \%$, specificity of $82 \%$, sensitivity of $39 \%$ for detecting MHE (Ozel Coskun and Ozen 2017). However, for the threshold of CFF, the researchers had different choices. Barone et al. evaluated that a CFF cut-off of $39 \mathrm{~Hz}$ is effective in predicting survival and the first episode of MHE in cirrhosis patients who had never experienced MHE. With progression of the Child-Pugh class, 
the prevalence of $\mathrm{CFF} \leq 39 \mathrm{~Hz}$ significantly increased (Barone et al. 2018). Greinert et al. found that most patients with a MELD score $>24$ and CFF $<43 \mathrm{~Hz}$ had MHE. They demonstrated that combination of CFF and MELD score may be used as a first diagnostic step to filter patients, in whom further MHE testing could be avoided. Specificity and sensitivity of a CFF cut-off of $43 \mathrm{~Hz}$ was $93.5 \%$ and $42.9 \%$. (Greinert et al. 2016).

EEG has been acknowledged to confirm the presence and predict the severity of HE. Recently, Olesen et al. found increased sample entropy of the EEG in patients with MHE. $\alpha$ activity is gradually replaced by slowed brain oscillations typically with $\theta$ in the frequency range $(4-8 \mathrm{~Hz})$ in the transition from an unimpaired mental state to HE (Olesen et al. 2016). Spectral EEG is a quantitative tool for diagnosis and assessment of the response to treatment in MHE. Spectral EEG analysis showed lower mean dominant frequency and higher $\theta$ relative power but lower $\alpha$ relative power in patients with MHE than in patients without MHE. Singh et al. found that with spectral EEG, $96 \%$ sensitivity, $84 \%$ specificity and $90 \%$ accuracy were obtained for diagnosis of MHE (Singh et al. 2016).

\section{Imaging}

Magnetic resonance imaging (MRI) applies electromagnetic waves emitted by a graded magnetic field to acquire the internal structure of the objects (Lockwood et al. 1991; Shawcross et al. 2007). The biomarker for MHE is altered regional brain spontaneous activity. For example, the mean kurtosis values in the putamen decrease in the globus pallidus, putamen, caudate nucleus, and/or thalamus in patients with MHE (Sato et al. 2019). Chen et al. demonstrated that the amplitude of low frequency fluctuation (ALFF) values within six regions of interest (ROIs) correlated with PHES in cirrhosis patients. The ROIs contains the posterior cingulate cortex/precuneus, bilateral medial frontal cortex/anterior cingulate cortex, right lingual gyrus, the left precentral and postcentral gyrus, inferior/ superior parietal and middle frontal gyrus lobule (Chen et al. 2016). Zhong et al. also found that patients with MHE had significant decreased ALFF (Zhong et al. 2016). Default mode network function, especially the medial prefrontal cortex, might also be a useful imaging marker for differentiating MHE from cirrhosis. The MHE patients showed even more decreased connectivity in medial prefrontal cortex, left superior frontal gyrus, and right middle temporal gyri when compared with non-MHE patients (Qi et al. 2014).

Different kinds of MRI play an important role in the detection of MHE. Kooka et al. demonstrated magnetic resonance spectroscopy, which shows that reduced magnetization transfer ratio in the whole brain field and an increase in glutamate/ glutamine or taurine in chronic HE patients contribute to early and objective diagnosis of MHE. The levels of brain glutamine were significantly lower and the levels of brain myo-inositol were significantly higher in the control group compared with the MHE group (Kale et al. 2006; Kooka et al. 2016; Rovira et al. 2001). Altered diffusion kurtosis imaging metrics indicate brain microstructure abnormalities in MHE patients. Significantly alterations in axial diffusivity, radial diffusivity, and MD in a wide range of regions, including corpus callosum, left thalamus, were closely correlated with cognitive score (Li et al. 2019). Diffusion tensor imaging can differentiate MHE from non-MHE patients. Chen et al. found that in MD or fractional anisotropy maps, two spatially distributed white matter regions yielded $75.4-81.5 \%$ and 83.1-92.3\% classification accuracy when differentiating patients with and without MHE (Chen et al. 2015).

\section{Inflammatory cytokines}

In addition to hyperammonemia, inflammation also modulates neuropsychological function in patients with MHE. For example, Circulating IL-6 is negatively associated with memory function in low-dose endotoxemia (Krabbe et al. 2005; Tsai et al. 2015), serum IL-6 and IL-17a levels are independent risk factors for MHE in HBVinfected patients ( $\mathrm{Li}$ et al. 2015), IL-1 $\beta$ is a potential, independent predictor of MHE (Wunsch et al. 2013), patients with MHE have significantly higher TNF- $\alpha$ is significant higher in MHE patients (Srivastava et al. 2011). These inflammatory cytokines may become biomarkers for MHE diagnosis, but further researches are needed.

\section{Comparison}

Paper-and-pencil test used in PHES is the gold standard for diagnosis of MHE. But the process of diagnosis of PHES is inconvenient and affected by many factors. The diagnostic methods take time, and are affected by demographic factors, and lack ecological validity and language functions, such as verbal memory. PHES focuses on only two cognitive domains but it is not sensitive enough to detect early neurological alterations. Patients classified as without MHE by PHES have a high risk of suffering overt HE. Around $40 \%$ of patients without MHE according to PHES fail two other psychometric tests (Bajaj 2008 a; Gimenez-Garzo et al. 2017; Nardone et al. 2016; Seo et al. 2017; Wang et al. 2008). Other kinds of psychometric tests also have limitations. The ICT, which is a computerized test of response inhibition and working memory, requires highly functional patients. The Stroop app, which evaluates psychomotor speed and cognitive flexibility, is also a complex task that is applicable in highly functional patients (Bajaj et al. 2013). Tapper et al. conducted a meta-analysis to evaluate different kinds of psychometric tests. They compared ICT, Stroop app and ANT in diagnosis of MHE. They found that optimal cutoff for the Stroop app still varies. Good 
performance in the ICT, Stroop app or ANT is related to reduced development of $\mathrm{HE}$, but longitudinal data are still limited. Studies are needed in clinically representative populations with cutoffs validated (Tapper et al. 2018). However, psychometric tests are irreplaceable now because MHE has subtle abnormalities that can be detected only using specific neuropsychometric and/or neurophysiological tools in cirrhosis patients with otherwise normal neurological examination results (Stewart and Smith 2007). Among all psychometric tests, the ANT is reasonably widespread in humans of every culture, and the influence of gender, age and education, if any, might be limited (Campagna et al. 2017).

CFF is a noninvasive, rapid, simple test for diagnosis of MHE. Compared with PHES, CFF has a positive predictive value of $93.2 \pm 7.44 \%$, specificity of $92.7 \pm 7.96 \%$, negative predictive value of $90.4 \pm 8.91 \%$ and sensitivity of $91.1 \pm$ $8.32 \%$. CFF is excellent for diagnosis of MHE, with an area under the curve of 0.937 (Metwally et al. 2019). At one time, scientists thought EEG was an important method to predict MHE, but the detection of MHE showed limited agreement between PHES and EEG (Nardone et al. 2016). Meanwhile, it is difficult to make good use of EEG and CFF, as they are expensive, time-consuming, and dependent on specialist interpretation (Yoon et al. 2019). CFF is recommended as an adjunct (but not replacement) to psychometric testing.

Neuroimaging studies can detect diffuse abnormal metabolic activity of nerve cells, which is a typical feature of patients with MHE. MRI can provide objective and reliable imaging biomarkers that are necessary to help diagnose or identify MHE (Zhang et al. 2014). One major drawback of MRI concerns the lack of detection accuracy of the measured signal, but with technical advances, a solution to that problem is imminent (Janssen et al. 2018).

In addition to hyperammonemia, there is a parallel relationship between inflammatory cytokines and MHE, or a significant correlation between proinflammatory cytokines with MD values on diffusion tensor imaging (Srivastava et al. 2011) or PHES (Wunsch et al. 2013). However, there have been no studies on the accuracy and sensitivity of its application in the diagnosis of MHE, and more studies are expected.

Recent guidelines suggest that either alternative techniques, such as computerized tests, neurophysiological testing or EEG should be used alongside PHES for multicenter studies (Morgan et al. 2016; Vilstrup et al. 2014) (Table 1).

\section{Treatment of MHE: cognition recovery}

\section{Prevent nerve cells}

As mentioned above, nerve cell injury plays an important role in MHE progression, so protection of nerve cells is one way to prevent and treat MHE. Good nutritional status is an important way to relieve nerve cell damage. Myosteatosis and sarcopenia, probably by reducing the handling of ammonia in the muscle, are independently associated with MHE. Venous ammonia is significantly higher in patients with sarcopenia and myosteatosis and inversely correlated with both parameters (Nardelli et al. 2019). Wnt5a can reverse the decrease in spatial learning and memory in an MHE rat model. Down-regulation of neurotrophins, which are synthesized by Wnt5a, inhibits the interaction between Wnt5a and Frizzled-2 in astrocytes in MHE (Ding et al. 2017b).

Reducing neuroinflammation is also an important way to relieve nerve cell damage. Malaguarnera et al. demonstrated that bicuculline decreases anxiety and improves working memory and spatial learning in hyperammonemic rats. Bicuculline can reduce activation of GABAA receptors, which contributes to neuroinflammation. Meanwhile, bicuculline reduces astrocyte activation and not microglial activation. Bicuculline reverses the changes in membrane expression of AMPA and NMDA receptor subunits (Malaguarnera et al. 2019). Sulforaphane also can be useful in reducing neuroinflammation, normalizing membrane expression of glutamate and GABA receptors, restoring spatial learning, and improving cognitive function in cirrhosis patients with MHE, and promoting microglial differentiation from M1 to M2 phenotype and reducing activation of astrocytes in hyperammonemic rats (Hernandez-Rabaza et al. 2016). Sildenafil normalizes TNF- $\alpha$ and IL- $1 \beta$ levels, p38 phosphorylation, and membrane expression of NMDA, GABAA and AMPA receptors and restores spatial learning (Hernandez-Rabaza et al. 2015). Meanwhile, p38 inhibitor SB239063 can reduce inflammatory markers, as well as microglial activation. Agusti et al. showed that treatment with SB239063 completely restores coordination, motor activity, and learning ability in PCS rats (Agusti et al. 2011). Anti-TNF- $\alpha$, which does not cross the bloodbrain barrier, prevents hyperammonemia-induced neuroinflammation, alterations in microglial activation and cognitive impairment. This is also associated with altered membrane expression of glutamate receptors and impairment of spatial memory (Balzano et al. 2019).

\section{Regulate intestinal flora}

Disorder of intestinal flora and bacterial translocation, which increase production and absorption of intestinal toxins, are closely related to HE. There are different degrees of intestinal flora disorder in patients with chronic liver disease. Beneficial bacteria such as bifidobacteria are decreased while ureaseproducing bacteria are the source of gut-derived toxins. Production and absorption of intestinal toxins significantly increase, but the liver cannot metabolize these toxins completely, which leads to toxin retention (McPhail et al. 2010; Sanchez et al. 2005). 
MHE is also associated with individual microbiota signatures. For example, the relative abundance of Lactobacillaceae is higher in MHE, whereas abundance of autochthonous Lachnospiraceae is higher in those without MHE (Bajaj et al. 2019). Therefore, the adjustment of intestinal flora structure can also become an important way to treat MHE. For example, Xia et al. found that MHE patients' cognition was significantly improved after probiotic treatment. In the probiotics-treated group, Enterococcus and Enterobacteriaceae were significantly decreased while the predominant bacteria were significantly enriched (Xia et al. 2018). Probiotic, rifaximin, L-ornithine L-aspartate (LOLA) and lactulose are important for improving intestinal flora, which is associated with reduction in ammonia.

\section{Probiotics}

Probiotics are well-tolerated, natural and safe and appropriate for long-term treatment of MHE (Jiang et al. 2015). Probiotics can improve the parameters of the intestinal mucosal barrier, which might have contributed to decreased ammonia levels and improved cognition. Bajaj et al. demonstrated a significant rate of MHE reversal and excellent adherence in cirrhosis patients after probiotic yogurt supplementation with potential for long-term adherence. In their randomized controlled trial (RCT), patients taking yoghurt had an improved PHES score compared to baseline/no treatment group (Bajaj et al. 2008 b). In a meta-analysis of RCTs of the effects of probiotics on serum ammonia, endotoxin, and MHE, Cao et al. showed that probiotics were more likely to reduce values in the NCT, improve MHE, and prevent HE progression (Cao et al. 2018). However, short-term administration of probiotics when compared with placebo did not produce any significant improvement in patients with MHE. Saji et al. found no significant change in the parameters such as arterial ammonia, evoked responses and NCT before and after treatment with short-term probiotics when compared to placebo (Saji et al. 2011)

\section{Rifaximin}

Rifaximin is a non-absorbed, gut-selective antibiotic with a low resistance profile that is commonly used to treat HE. It achieves high concentrations in the human intestine, where it is active against many enteropathogens (Goel et al. 2017; Hudson and Schuchmann 2019).

Rifaximin has always been a second-line drug in the treatment of HE, but there are no unified conclusions for treatment of MHE. Bajaj et al. demonstrated that over the 8-week period, MHE patients treated with rifaximin showed significant improvements in avoiding total driving errors, speeding, and illegal turns. Rifaximin also made improvements in the psychosocial dimension of the sickness impact profile and the anti-inflammatory cytokine IL-10 levels (Bajaj et al. 2011). However, Schulz et al. demonstrated that rifaximin therapy with and without lactulose over a period of 3 months does not affect bacterial composition (Schulz et al. 2019).

\section{LOLA}

LOLA may be administered orally or parenterally. The benefits of LOLA for the treatment of HE have been known for 50 years (Buyeverov et al. 2019; Kircheis and Luth 2019). However, in the treatment of MHE, there are no unified conclusions about the efficacy of LOLA. Buyeverov et al. demonstrated that fractional treatment with LOLA decreases level of ammonium ions in the blood and improves psychometric test results consequently. After 1 month of LOLA treatment, the CFF test was significantly improved and remained at that level for 9 months. After 5 months treatment, the NCT parameters reached their minimum values and remained at that level throughout the study. (Buyeverov et al. 2019). Alvaresda-Silva et al. showed that LOLA was useful in preventing further episodes of $\mathrm{HE}$, but was no better in treating MHE (Alvares-da-Silva et al. 2014).

\section{Lactulose}

Lactulose is a disaccharide composed of galactose and fructose. As early as 1957, the prebiotic properties of lactulose were reported in both adults and infants. Due to promising outcomes, low price and high availability, Lactulose does not undergo cleavage by human gastrointestinal enzymes (Ruszkowski and Witkowski 2019; Schumann 2002). Lactulose may function as a prebiotic in the treatment of HE, so it can effectively modulate intestinal flora and reduce systemic level of ammonia. It significantly increases concentrations of bifidobacteria and lactobacilli; lactulose also can effectively inhibit urease-producing pathogenic bacteria like Enterobacteriaceae (Suraweera et al. 2016).

Psychometric tests improved in $75 \%$ of MHE patients after treatment with lactulose (El-Karaksy et al. 2017). In 2011, Luo et al. conducted a meta-analysis that demonstrated that lactulose significantly reduced the risk of no improvement in neuropsychological tests, the time required for the completion of the NCT-A, and the mean number of abnormal neuropsychological tests. Furthermore, lactulose prevented progression to overt HE, reduced blood ammonia levels, and improved health-related quality of life (Luo et al. 2011). Recent research has demonstrated the important role of lactulose in improving MHE. Singh et al. demonstrated that lactulose also leads to improvement in sleep disturbances in MHE patients (Singh et al. 2017). 
Table 2 Comparison of different kinds of drugs in improving MHE

\begin{tabular}{|c|c|c|}
\hline & Advantage & Disadvantage \\
\hline probiotic & $\begin{array}{l}i s \text { natural } \\
\sum^{2} \text { well-tolerated therapy }\end{array}$ & $\begin{array}{l}\text { tsafety, effectiveness and immune response } \\
\text { are unknown }\end{array}$ \\
\hline rifaximin & $\begin{array}{l}\text { ţexcellent adherence } \\
\text { tantibiotic with low resistance } \\
\text { tachieves high concentrations in intestine }\end{array}$ & $\begin{array}{l}\text { trost is relative high } \\
\text { tono significant side effect }\end{array}$ \\
\hline LOLA & $\begin{array}{l}\text { t3high availability } \\
\text { islow price }\end{array}$ & țno significant disadvantage \\
\hline lactulose & $\begin{array}{l}\text { shigh availability } \\
\text { slow price } \\
\text { spromising outcomes }\end{array}$ & $\begin{array}{l}\text { tsflatulence } \\
\text { todiarrhea } \\
\text { ţabdominal pain } \\
\text { tsintestinal malabsorption } \\
\text { tspoor compliance for the long-term treatment }\end{array}$ \\
\hline
\end{tabular}

\section{Comparison}

Probiotics, rifaximin, LOLA and lactulose can improve MHE, but they also have some weaknesses (Table 2). Probiotics have not undergone rigorous clinical trials, because they were considered more as health supplements or food. But more and more research demonstrated the safety and efficacy of probiotics for individual recipients were determined by host-microbe and host biochemical milieu interactions. So the potency of microbial species formulations, dosage, the immune response and strain-specific health effects must be studied (Hammerman et al. 2006; Sanders et al. 2010). Lactulose causes abdominal pain, diarrhea, intestinal malabsorption or flatulence. Lactulose may not be the optimal therapy for MHE patients due to poor compliance, cost, and adverse effects (Sharma et al. 2010). No significant adverse effects were observed with rifaximin and LOLA. However, the cost of rifaximin is high and patient compliance is not optimized (Butterworth and McPhail 2019; Chen et al. 2005; Goh et al. 2018; Lyon et al. 2017).

In recent years, many scientists have compared the efficacy of these drugs in preventing and treating MHE, and there was no difference between probiotics and lactulose (Jiang et al. 2015). However, another study found that probiotics have long-term effects compared with lactulose (Shavakhi et al. 2014). Sidhu et al. conducted an RCT in which patients were randomized to treatment with lactulose or rifaximin. However, noninferiority of rifaximin over lactulose could not be established and health-related quality of life was significantly improved in both groups (Sidhu et al. 2016). Zuo et al. demonstrated that treatment with rifaximin plus probiotics exhibited a different effect in MHE patients. The addition of probiotics to the treatment regimen distorted the distribution of bacteria and reduced Streptococcus abundance in the gut (Zuo et al. 2017).
Butterworth et al. conducted a meta-analysis to compare the efficiency of LOLA, lactulose, probiotics and rifaximin in MHE patients. LOLA was comparable to the alternatives for both for slowing progression from MHE to HE and reversal of deficits in psychometric test scores (Butterworth and McPhail 2019).

Given the adverse effects of lactulose, cost of rifaximin and the safety of probiotics, LOLA appears to have beneficial effects in MHE, although its role in therapy is not clearly defined (Table 2).

\section{Discussion}

MHE has serious consequences for quality of life, increasing the number of accidents, falls, hospitalizations and associated costs (Llansola et al. 2015). Ammonia or other liver abnormal metabolites can diffuse through the blood brain barrier in MHE patients. Then nerve cells, including astrocytes, microglial and neurons were damaged by DA, etc. Furthermore, cognitive areas, such as the hippocampus are affected (Fig. 1).

Timely and accurate discovery of cognitive impairment is the key to diagnosis of MHE. Psychometric tests, CFF, EEG and MRI are useful to evaluate cognitive function in an intuitive or abstract way. Psychometric tests are irreplaceable now. Compared with other psychometric tests, ANT is little influenced by age and education level. MRI, which can more accurately reflect changes in cognitive function, may be the best option in the future, if the problem of lack of detection accuracy of the measured signal can be resolved. CFF and EEG should be used alongside PHES (Table 1).

Timely correction of cognitive impairment is the key to treatment of MHE. One method is to prevent nerve cell injury, through improving the nutritional status of nerve cells, and blocking their injury by inflammatory mediators. Another method is to improve intestinal flora and reduce serum 
ammonia level. Among the drugs to improve intestinal flora, LOLA has few adverse effects and low cost, which may become the ideal choice in the future (Table 2).

Acknowledgements This article was supported by (1) National Key R\&D Program of China (No.2017YFA0103000); (2) Beijing Municipal Administration of Hospitals Clinical Medicine Development of Special Funding Support (No.ZYLX201806); (3) "Beijing Muncipal Administration of Hospitals" Ascent Plan (No. DFL20151601); (4) National Science and Technology Key Project on "Major Infectious Diseases such as HIV/AIDS, Viral Hepatitis Preventon and Treatment" (NO. 2012ZX10002004-006,2017ZX10203201-005, 2017ZX10201201-001-001, 2017ZX10201201-002-002, 2017ZX10202203-006-001, 2017ZX10302201-004-002).

\section{Compliance with ethical standards}

\section{Conflict of interest The authors declare no competing interests.}

Open Access This article is licensed under a Creative Commons Attribution 4.0 International License, which permits use, sharing, adaptation, distribution and reproduction in any medium or format, as long as you give appropriate credit to the original author(s) and the source, provide a link to the Creative Commons licence, and indicate if changes were made. The images or other third party material in this article are included in the article's Creative Commons licence, unless indicated otherwise in a credit line to the material. If material is not included in the article's Creative Commons licence and your intended use is not permitted by statutory regulation or exceeds the permitted use, you will need to obtain permission directly from the copyright holder. To view a copy of this licence, visit http://creativecommons.org/licenses/by/4.0/.

\section{References}

Agusti A, Cauli O, Rodrigo R, Llansola M, Hernandez-Rabaza V, Felipo $\mathrm{V}$ (2011) p38 MAP kinase is a therapeutic target for hepatic encephalopathy in rats with portacaval shunts. Gut 60:1572-1579

Alvares-da-Silva MR, de Araujo A, Vicenzi JR, da Silva GV, Oliveira FB, Schacher F, Oliboni L, Magnus A, Kruel LP, Prieb R, Fernandes LN (2014) Oral 1-ornithine-l-aspartate in minimal hepatic encephalopathy: a randomized, double-blind, placebo-controlled trial. Hepatol Res 44:956-963

Arias N, Mendez M, Gomez-Lazaro E, Azpiroz A, Arias JL (2015) Main target of minimal hepatic encephalopathy: Morphophysiological, inflammatory and metabolic view. Physiol Behav 149:247-254

Badea MA, Drug VL, Dranga M, Gavrilescu O, Stefanescu G, Popa I, Mihai C, Cijevschi-Prelipcean C (2016) Diagnosis of minimal hepatic encephalopathy in a tertiary care center from eastern Romania: validation of the psychometric hepatic encephalopathy score (PHES). Metab Brain Dis 31:1463-1471

Bajaj JS (2008) Minimal hepatic encephalopathy matters in daily life. World J Gastroenterol 14:3609-3615

Bajaj JS, Fagan A, White MB, Wade JB, Hylemon PB, Heuman DM, Fuchs M, John BV, Acharya C, Sikaroodi M, Gillevet PM (2019) Specific gut and salivary microbiota patterns are linked with different cognitive testing strategies in minimal hepatic encephalopathy. Am J Gastroenterol 114:1080-1090

Bajaj JS, Heuman DM, Wade JB, Gibson DP, Saeian K, Wegelin JA, Hafeezullah M, Bell DE, Sterling RK, Stravitz RT, Fuchs M, Luketic V, Sanyal AJ (2011) Rifaximin improves driving simulator performance in a randomized trial of patients with minimal hepatic encephalopathy. Gastroenterology 140(478-487):e471

Bajaj JS, Saeian K, Christensen KM, Hafeezullah M, Varma RR, Franco J, Pleuss JA, Krakower G, Hoffmann RG, Binion DG (2008) Probiotic yogurt for the treatment of minimal hepatic encephalopathy. Am J Gastroenterol 103:1707-1715

Bajaj JS, Thacker LR, Heuman DM, Fuchs M, Sterling RK, Sanyal AJ, Puri P, Siddiqui MS, Stravitz RT, Bouneva I, Luketic V, Noble N, White MB, Monteith P, Unser A, \&Wade JB (2013) The Stroop smartphone application is a short and valid method to screen for minimal hepatic encephalopathy. Hepatology 58: 1122-1132

Balzano T, Dadsetan S, Forteza J, Cabrera-Pastor A, Taoro-Gonzalez L, Malaguarnera M, Gil-Perotin S, Cubas-Nunez L, Casanova B, Castro-Quintas A, Ponce-Mora A, Arenas YM, Leone P, Llansola M, Felipo V (2019) Chronic hyperammonemia induces peripheral inflammation that leads to cognitive impairment in rats: reversal by anti-tnfa treatment. J Hepatol

Barone M, Shahini E, Iannone A, Viggiani MT, Corvace V, Principi M, Di Leo A (2018) Critical flicker frequency test predicts overt hepatic encephalopathy and survival in patients with liver cirrhosis. Dig Liver Dis 50:496-500

Butterworth RF, McPhail MJW (2019) L-ornithine L-aspartate (LOLA) for hepatic encephalopathy in cirrhosis: results of randomized controlled trials and meta-analyses. Drugs 79:31-37

Buyeverov AO, Bogomolov PO, Mayev IV, Matsievich MV, Uvarova OV (2019) Possibilities of therapeutic correction of hyperammonemia and minimal hepatic encephalopathy in patients with chronic hepatitis $\mathrm{C}$ at the pre-cirrhotic stage. Terapevticheskii Arkhiv 91:52-58

Cabrera-Pastor A, Hernandez-Rabaza V, Taoro-Gonzalez L, Balzano T, Llansola M, Felipo V (2016) In vivo administration of extracellular cGMP normalizes TNF-alpha and membrane expression of AMPA receptors in hippocampus and spatial reference memory but not IL1 beta, NMDA receptors in membrane and working memory in hyperammonemic rats. Brain Behav Immun 57:360-370

Cabrera-Pastor A, Llansola M, Montoliu C, Malaguarnera M, Balzano T, Taoro-Gonzalez L, Garcia-Garcia R, Mangas-Losada A, IzquierdoAltarejos P, Arenas YM, Leone P, Felipo V (2019) Peripheral inflammation induces neuroinflammation that alters neurotransmission and cognitive and motor function in hepatic encephalopathy: underlying mechanisms and therapeutic implications. Acta Physiol (Oxf) 226:e13270

Campagna F, Montagnese S, Ridola L, Senzolo M, Schiff S, De Rui M, Pasquale C, Nardelli S, Pentassuglio I, Merkel C, Angeli P, Riggio O, Amodio P (2017) The animal naming test: an easy tool for the assessment of hepatic encephalopathy. Hepatology 66:198-208

Cao Q, Yu CB, Yang SG, Cao HC, Chen P, Deng M, Li LJ (2018) Effect of probiotic treatment on cirrhotic patients with minimal hepatic encephalopathy: a meta-analysis. Hepatobiliary \& Pancreatic Diseases International 17:9-16

Chen HJ, Chen R, Yang M, Teng GJ, Herskovits EH (2015) Identification of minimal hepatic encephalopathy in patients with cirrhosis based on white matter imaging and Bayesian data mining. AJNR Am J Neuroradiol 36:481-487

Chen HJ, Zhang L, Jiang LF, Chen QF, Li J, Shi HB (2016) Identifying minimal hepatic encephalopathy in cirrhotic patients by measuring spontaneous brain activity. Metab Brain Dis 31:761-769

Chen MF, Li RC, Chen CH, Gao XC (2005) [Therapeutic effect of Lornithine-L-aspartate on liver cirrhosis complicated by hepatic encephalopathy]. Di 1 Jun Yi Da Xue Xue Bao. Academic Journal of the First Medical College of Pla 25:718-719 722

Chepkova AN, Sergeeva OA, Gorg B, Haas HL, Klocker N, Haussinger D (2017) Impaired novelty acquisition and synaptic plasticity in congenital hyperammonemia caused by hepatic glutamine synthetase deficiency. Sci Rep 7:40190 
Coskun B, Ozen M, Gursoy S, Ozbakir O, Poyrazoglu OK, Baskol M, Sezgin GC, Yucesoy M (2017) Normalization of the psychometric hepatic encephalopathy score for diagnosis of minimal hepatic encephalopathy in Turkey. Niger J Clin Pract 20:421-426

Di Lemma LCG, Field M (2017) Cue avoidance training and inhibitory control training for the reduction of alcohol consumption: a comparison of effectiveness and investigation of their mechanisms of action. Psychopharmacology 234:2489-2498

Ding S, Wang W, Wang X, Liang Y, Liu L, Ye Y, Yang J, Gao H, Zhuge Q (2016) Dopamine burden triggers Neurodegeneration via production and release of TNF-alpha from astrocytes in minimal hepatic encephalopathy. Mol Neurobiol 53:5324-5343

Ding S, Wang X, Zhuge W, Yang J, Zhuge Q (2017a) Dopamine induces glutamate accumulation in astrocytes to disrupt neuronal function leading to pathogenesis of minimal hepatic encephalopathy. Neuroscience 365:94-113

Ding S, Xu Z, Yang J, Liu L, Huang X, Wang X, Zhuge Q (2017b) The involvement of the decrease of Astrocytic Wnt5a in the cognitive decline in minimal hepatic encephalopathy. Mol Neurobiol 54: 7949-7963

Ding S, Yang J, Liu L, Ye Y, Wang X, Hu J, Chen B, Zhuge Q (2014) Elevated dopamine induces minimal hepatic encephalopathy by activation of astrocytic NADPH oxidase and astrocytic protein tyrosine nitration. International Journal of Biochemistry \& Cell Biology $55: 252-263$

Ding S, Zhuge W, Yang J, Wen F, Xu Z, Wang X, Zhuge Q (2018) Insulin resistance disrupts the interaction between AKT and the NMDA receptor and the inactivation of the CaMKIV/CREB pathway in minimal hepatic encephalopathy. Toxicol Sci 161:208

Dossi E, Vasile F, Rouach N (2018) Human astrocytes in the diseased brain. Brain Res Bull 136:139-156

El-Karaksy HM, Afifi O, Bakry A, Kader AA, Saber N (2017) A pilot study using lactulose in management of minimal hepatic encephalopathy in children with extrahepatic portal vein obstruction. World J Pediatr 13:70-75

Felipo V, Urios A, Montesinos E, Molina I, Garcia-Torres ML, Civera M, Olmo JA, Ortega J, Martinez-Valls J, Serra MA, Cassinello N, Wassel A, Jorda E, Montoliu C (2012) Contribution of hyperammonemia and inflammatory factors to cognitive impairment in minimal hepatic encephalopathy. Metab Brain Dis 27:5158

Ferenci P, Lockwood A, Mullen K, Tarter R, Weissenborn K, Blei AT (2002) Hepatic encephalopathy-definition, nomenclature, diagnosis, and quantification: final report of the working party at the 11th world congresses of gastroenterology, Vienna, 1998. Hepatology 35:716-721

Fumagalli M, Lombardi M, Gressens P, Verderio C (2018) How to reprogram microglia toward beneficial functions. Glia 66:2531-2549

Gimenez-Garzo C, Garces JJ, Urios A, Mangas-Losada A, Garcia-Garcia R, Gonzalez-Lopez O, Giner-Duran R, Escudero-Garcia D, Serra MA, Soria E, Felipo V, Montoliu C (2017) The PHES battery does not detect all cirrhotic patients with early neurological deficits, which are different in different patients. PLoS One 12:e0171211

Goel A, Rahim U, Nguyen LH, Stave C, Nguyen MH (2017) Systematic review with meta-analysis: rifaximin for the prophylaxis of spontaneous bacterial peritonitis. Aliment Pharmacol Ther 46:1029-1036

Goh ET, Stokes CS, Sidhu SS, Vilstrup H, Gluud LL, Morgan MY (2018) L-ornithine L-aspartate for prevention and treatment of hepatic encephalopathy in people with cirrhosis. Cochrane Database Syst Rev 5:CD012410

Greinert R, Ripoll C, Hollenbach M, Zipprich A (2016) Stepwise diagnosis in covert hepatic encephalopathy: critical flicker frequency and MELD-score as a first-step approach. Aliment Pharmacol Ther 44:514-521

Gupta D, Ingle M, Shah K, Phadke A, Sawant P (2015) Prospective comparative study of inhibitory control test and psychometric hepatic encephalopathy score for diagnosis and prognosis of minimal hepatic encephalopathy in cirrhotic patients in the Indian subcontinent. J Dig Dis 16:400-407

Hammerman C, Bin-Nun A, Kaplan M (2006) Safety of probiotics: comparison of two popular strains. BMJ 333:1006-1008

Hartmann L, Wachtl L, de Lucia M, Spierer L (2019) Practice-induced functional plasticity in inhibitory control interacts with aging. Brain Cogn 132:22-32

Hernandez-Rabaza V, Agusti A, Cabrera-Pastor A, Fustero S, Delgado O, Taoro-Gonzalez L, Montoliu C, Llansola M, Felipo V (2015) Sildenafil reduces neuroinflammation and restores spatial learning in rats with hepatic encephalopathy: underlying mechanisms. J Neuroinflammation 12:195

Hernandez-Rabaza V, Cabrera-Pastor A, Taoro-Gonzalez L, Malaguarnera M, Agusti A, Llansola M, Felipo V (2016) Hyperammonemia induces glial activation, neuroinflammation and alters neurotransmitter receptors in hippocampus, impairing spatial learning: reversal by sulforaphane. J Neuroinflammation 13:41

Hudson M, Schuchmann M (2019) Long-term management of hepatic encephalopathy with lactulose and/or rifaximin: a review of the evidence. Eur J Gastroenterol Hepatol 31:434-450

Jackson JG, Robinson MB (2018) Regulation of mitochondrial dynamics in astrocytes: mechanisms, consequences, and unknowns. Glia 66: $1213-1234$

Janssen N, Hernandez-Cabrera JA, Foronda LE (2018) Improving the signal detection accuracy of functional magnetic resonance imaging. Neuroimage 176:92-109

Jiang SM, Jia L, Zhang MH (2015) Probiotic and lactulose: influence on gastrointestinal flora and $\mathrm{pH}$ value in minimal hepatic encephalopathy rats. Int J Clin Exp Med 8:9996-10000

Jiao Y, Wang XH, Chen R, Tang TY, Zhu XQ, Teng GJ (2017) Predictive models of minimal hepatic encephalopathy for cirrhotic patients based on large-scale brain intrinsic connectivity networks. Sci Rep 7:11512

Kale RA, Gupta RK, Saraswat VA, Hasan KM, Trivedi R, Mishra AM, Ranjan P, Pandey CM, Narayana PA (2006) Demonstration of interstitial cerebral edema with diffusion tensor MR imaging in type $\mathrm{C}$ hepatic encephalopathy. Hepatology 43:698-706

Kircheis G, Luth S (2019) Pharmacokinetic and Pharmacodynamic properties of L-ornithine L-aspartate (LOLA) in hepatic encephalopathy. Drugs 79:23-29

Kooka Y, Sawara K, Endo R, Kato A, Suzuki K, Takikawa Y (2016) Brain metabolism in minimal hepatic encephalopathy assessed by 3.0-tesla magnetic resonance spectroscopy. Hepatol Res 46:269276

Krabbe KS, Reichenberg A, Yirmiya R, Smed A, Pedersen BK, Bruunsgaard H (2005) Low-dose endotoxemia and human neuropsychological functions. Brain Behav Immun 19:453-460

Kulkarni VV, Maday S (2018) Compartment-specific dynamics and functions of autophagy in neurons. Developmental Neurobiology 78:298-310

Labenz C, Beul L, Toenges G, Schattenberg JM, Nagel M, Sprinzl MF, Nguyen-Tat M, Zimmermann T, Huber Y, Marquardt JU, Galle PR, Worns MA (2019) Validation of the simplified animal naming test as primary screening tool for the diagnosis of covert hepatic encephalopathy. European Journal of Internal Medicine 60:96-100

Li JL, Jiang H, Zhang XD, Huang LX, Xie SS, Zhang L, Cheng Y, Shen W (2019) Microstructural brain abnormalities correlate with neurocognitive dysfunction in minimal hepatic encephalopathy: a diffusion kurtosis imaging study. Neuroradiology 61:685-694

Li W, Li N, Wang R, Li Q, Wu H (2015) Interferon gamma, interleukin6 , and -17 a levels were correlated with minimal hepatic encephalopathy in HBV patients. Hepatol Int 9:218-223

Llansola M, Montoliu C, Agusti A, Hernandez-Rabaza V, Cabrera-Pastor A, Gomez-Gimenez B, Malaguarnera M, Dadsetan S, Belghiti M, Garcia-Garcia R, Balzano T, Taoro L, Felipo V (2015) Interplay 
between glutamatergic and GABAergic neurotransmission alterations in cognitive and motor impairment in minimal hepatic encephalopathy. Neurochem Int 88:15-19

Lockwood AH, Yap EW, Wong WH (1991) Cerebral ammonia metabolism in patients with severe liver disease and minimal hepatic encephalopathy. J Cereb Blood Flow Metab 11:337-341

Luo M, Li L, Lu CZ, Cao WK (2011) Clinical efficacy and safety of lactulose for minimal hepatic encephalopathy: a meta-analysis. Eur J Gastroenterol Hepatol 23:1250-1257

Luo M, Ma P, Li L, Cao WK (2019) Advances in psychometric tests for screening minimal hepatic encephalopathy: from paper-and-pencil to computer-aided assessment. Turk J Gastroenterol 30:398-407

Lyon KC, Likar E, Martello JL, Regier M (2017) Retrospective crosssectional pilot study of rifaximin dosing for the prevention of recurrent hepatic encephalopathy. J Gastroenterol Hepatol 32:1548-1552

Malaguarnera M, Llansola M, Balzano T, Gomez-Gimenez B, AntunezMunoz C, Martinez-Alarcon N, Mahdinia R, Felipo V (2019) Bicuculline reduces neuroinflammation in hippocampus and improves spatial learning and anxiety in hyperammonemic rats. Role of glutamate receptors. Front Pharmacol 10:132

McPhail MJ, Bajaj JS, Thomas HC, Taylor-Robinson SD (2010) Pathogenesis and diagnosis of hepatic encephalopathy. Expert Rev Gastroenterol Hepatol 4:365-378

Metwally MA, Biomy HA, Omar MZ, Sakr AI (2019) Critical flickering frequency test: a diagnostic tool for minimal hepatic encephalopathy. Eur J Gastroenterol Hepatol 31:1030-1034

Morgan MY, Amodio P, Cook NA, Jackson CD, Kircheis G, Lauridsen MM, Montagnese S, Schiff S, Weissenborn K (2016) Qualifying and quantifying minimal hepatic encephalopathy. Metab Brain Dis 31:1217-1229

Nardelli S, Lattanzi B, Merli M, Farcomeni A, Gioia S, Ridola L, Riggio O (2019) Muscle alterations are associated with minimal and overt hepatic encephalopathy in patients with liver cirrhosis. Hepatology

Nardone R, Taylor AC, Holler Y, Brigo F, Lochner P, Trinka E (2016) Minimal hepatic encephalopathy: a review. Neurosci Res 111:1-12

Olesen SS, Gram M, Jackson CD, Halliday E, Sandberg TH, Drewes AM, Morgan MY (2016) Electroencephalogram variability in patients with cirrhosis associates with the presence and severity of hepatic encephalopathy. J Hepatol 65:517-523

Ozel Coskun BD, Ozen M (2017) Critical flicker frequency test for diagnosing minimal hepatic encephalopathy in patients with cirrhosis. Turk J Gastroenterol 28:191-196

Qi R, Zhang LJ, Luo S, Ke J, Kong X, Xu Q, Liu C, Lu H, Lu GM (2014) Default mode network functional connectivity: a promising biomarker for diagnosing minimal hepatic encephalopathy: CONSORT-compliant article. Medicine (Baltimore) 93:e227

Ridola L, Nardelli S, Gioia S, Riggio O (2018) Quality of life in patients with minimal hepatic encephalopathy. World J Gastroenterol 24: $5446-5453$

Rovira A, Grive E, Pedraza S, Rovira A, Alonso J (2001) Magnetization transfer ratio values and proton MR spectroscopy of normalappearing cerebral white matter in patients with liver cirrhosis. AJNR Am J Neuroradiol 22:1137-1142

Ruszkowski J, Witkowski JM (2019) Lactulose: patient- and dosedependent prebiotic properties in humans. Anaerobe 59:100-106

Saji S, Kumar S, Thomas V (2011) A randomized double blind placebo controlled trial of probiotics in minimal hepatic encephalopathy. Trop Gastroenterol 32:128-132

Sanchez E, Casafont F, Guerra A, de Benito I, Pons-Romero F (2005) Role of intestinal bacterial overgrowth and intestinal motility in bacterial translocation in experimental cirrhosis. Rev Esp Enferm Dig 97:805-814

Sanders ME, Akkermans LM, Haller D, Hammerman C, Heimbach J, Hormannsperger G, Huys G, Levy DD, Lutgendorff F, Mack D, Phothirath P, Solano-Aguilar G, Vaughan E (2010) Safety assessment of probiotics for human use. Gut Microbes 1:164-185
Sato T, Endo K, Kakisaka K, Suzuki Y, Kooka Y, Sawara K, Ito K, Sasaki M, Takikawa Y (2019) Decreased mean kurtosis in the putamen is a diagnostic feature of minimal hepatic encephalopathy in patients with cirrhosis. Intern Med 58:1217-1224

Schulz C, Schutte K, Vilchez-Vargas R, Vasapolli R, Malfertheiner P (2019) Long-term effect of Rifaximin with and without lactulose on the active bacterial assemblages in the proximal small bowel and Faeces in patients with minimal hepatic encephalopathy. Dig Dis $37: 161-169$

Schumann C (2002) Medical, nutritional and technological properties of lactulose. An update European Journal of Nutrition 41(Suppl 1): I17-I25

Seo K, Jun DW, Kim JK, Ryu H (2017) Multi-sensory integration impairment in patients with minimal hepatic encephalopathy. Sci Rep $7: 14947$

Sharma P, Sharma BC, Sarin SK (2010) Predictors of nonresponse to lactulose in patients with cirrhosis and hepatic encephalopathy. Eur J Gastroenterol Hepatol 22:526-531

Shavakhi A, Hashemi H, Tabesh E, Derakhshan Z, Farzamnia S, Meshkinfar S, Shavakhi S, Minakari M, Gholamrezaei A (2014) Multistrain probiotic and lactulose in the treatment of minimal hepatic encephalopathy. Journal of Research in Medical Sciences 19: 703-708

Shawcross DL, Wright G, Olde Damink SW, Jalan R (2007) Role of ammonia and inflammation in minimal hepatic encephalopathy. Metab Brain Dis 22:125-138

Sidhu SS, Goyal O, Parker RA, Kishore H, Sood A (2016) Rifaximin vs. lactulose in treatment of minimal hepatic encephalopathy. Liver Int $36: 378-385$

Singh J, Sharma BC, Maharshi S, Puri V, Srivastava S (2016) Spectral electroencephalogram in liver cirrhosis with minimal hepatic encephalopathy before and after lactulose therapy. J Gastroenterol Hepatol 31:1203-1209

Singh J, Sharma BC, Puri V, Sachdeva S, Srivastava S (2017) Sleep disturbances in patients of liver cirrhosis with minimal hepatic encephalopathy before and after lactulose therapy. Metab Brain Dis 32:595-605

Srivastava A, Yadav SK, Yachha SK, Thomas MA, Saraswat VA, Gupta RK (2011) Pro-inflammatory cytokines are raised in extrahepatic portal venous obstruction, with minimal hepatic encephalopathy. J Gastroenterol Hepatol 26:979-986

Stewart CA, Smith GE (2007) Minimal hepatic encephalopathy. Nature Clinical Practice: Gastroenterology \& Hepatology 4:677-685

Stinton LM, Jayakumar S (2013) Minimal hepatic encephalopathy. Can J Gastroenterol 27:572-574

Stravitz RT, Gottfried M, Durkalski V, Fontana RJ, Hanje AJ, Koch D, Hameed B, Ganger D, Subramanian RM, Bukofzer S, Ravis WR, Clasen K, Sherker A, Little L, Lee WM, Acute Liver Failure Study G (2018) Safety, tolerability, and pharmacokinetics of 1-ornithine phenylacetate in patients with acute liver injury/failure and hyperammonemia. Hepatology 67:1003-1013

Suraweera D, Sundaram V, Saab S (2016) Evaluation and Management of Hepatic Encephalopathy: current status and future directions. Gut Liver 10:509-519

Tapper EB, Parikh ND, Waljee AK, Volk M, Carlozzi NE, Lok AS (2018) Diagnosis of minimal hepatic encephalopathy: a systematic review of point-of-care diagnostic tests. Am J Gastroenterol 113: 529-538

Tsai CF, Chu CJ, Huang YH, Wang YP, Liu PY, Lin HC, Lee FY, Lu CL (2015) Detecting minimal hepatic encephalopathy in an endemic country for hepatitis B: the role of psychometrics and serum IL-6. PLoS One 10:e0128437

Vilstrup H, Amodio P, Bajaj J, Cordoba J, Ferenci P, Mullen KD, Weissenborn K, Wong P (2014) Hepatic encephalopathy in chronic liver disease: 2014 practice guideline by the American Association 
for the Study of Liver Diseases and the European Association for the Study of the liver. Hepatology 60:715-735

Wang J, Li R, Guo C, Fournier C, W KW (2008) The influence of fractionation on cell survival and premature differentiation after carbon ion irradiation. J Radiat Res 49:391-398

Wang Y, Shi XJ, Abuduheilili X, Fan XT, Ma HL, Feng J, Sun J, A LY, He FP (2013) Critical flicker frequency for the diagnosis of minimal hepatic encephalopathy. Zhonghua Gan Zang Bing Za Zhi 21:546547

Wuensch T, Ruether DF, Zollner C, Mueller T, Jung T, Kaffarnik M, Kassner U, Schott E, Kiefer S, Pratschke J, Stockmann M, Jara M (2017) Performance characterization of a novel electronic number connection test to detect minimal hepatic encephalopathy in cirrhotic patients. Eur J Gastroenterol Hepatol 29:456-463

Wunsch E, Koziarska D, Milkiewicz M, Naprawa G, Nowacki P, Hartleb M, Milkiewicz P (2013) In patients with liver cirrhosis, proinflammatory interleukins correlate with health-related quality of life irrespective of minimal hepatic encephalopathy. Eur J Gastroenterol Hepatol 25:1402-1407

Xia X, Chen J, Xia J, Wang B, Liu H, Yang L, Wang Y, Ling Z (2018) Role of probiotics in the treatment of minimal hepatic encephalopathy in patients with HBV-induced liver cirrhosis. J Int Med Res 46: 3596-3604

Yoon EL, Jun DW, Jeong JY, Kim TY, Song DS, Ahn SB, Kim HY, Jung YK, Song MJ, Kim SE, Kim HS, Jeong SW, Kim
SG, Lee TH, Cho YK, Kim JK, Ryu H (2019) Validation of the Korean Stroop test in diagnosis of minimal hepatic encephalopathy. Sci Rep 9:8027

Zeng X, Li XX, Shi PM, Zhang YY, Song Y, Liu Q, Wei L, Bajaj JS, Zhu YH, Li Y, Gu Y, Xie WF, Liu YL (2019) Utility of the EncephalApp Stroop test for covert hepatic encephalopathy screening in Chinese cirrhotic patients. J Gastroenterol Hepatol

Zhang XD, Zhang LJ, Wu SY, Lu GM (2014) Multimodality magnetic resonance imaging in hepatic encephalopathy: an update. World J Gastroenterol 20:11262-11272

Zhong WJ, Zhou ZM, Zhao JN, Wu W, Guo DJ (2016) Abnormal spontaneous brain activity in minimal hepatic encephalopathy: restingstate fMRI study. Diagn Interv Radiol 22:196-200

Zhuge W, Wen F, Ni Z, Zheng Z, Zhu X, Lin J, Wang J, Zhuge Q, Ding S (2019) Dopamine burden triggers cholesterol overload following disruption of synaptogenesis in minimal hepatic encephalopathy. Neuroscience 410:1-15

Zuo Z, Fan H, Tang XD, Chen YM, Xun LT, Li Y, Song ZJ, Zhai HQ (2017) Effect of different treatments and alcohol addiction on gut microbiota in minimal hepatic encephalopathy patients. Exp Therap Med 14:4887-4895

Publisher's note Springer Nature remains neutral with regard to jurisdictional claims in published maps and institutional affiliations. 